\title{
Articulações interinstitucionais na realização de feiras agroecológicas na Microrregião de Campina Grande-PB
}

Ramonildes Alves Gomes

Programa de Pós-Graduação em Ciências Sociais da Universidade Federal de Campina Grande (Ufcg)

Thiago Lima Matias

Mestrando do Programa de Pós-Graduação em Desenvolvimento Regional da Universidade Estadual da Paraíba

(Uepb)

Jonatta Sousa Paulino

Doutorando do Programa de Pós-Graduação em Ciências Sociais da Universidade Federal de Campina Grande

(Ufcg)

Recebido: 02/07/2015 Versão revisada (entregue): 14/08/2015 Aprovado: 18/08/2015

\begin{abstract}
Resumo
Dentre as estratégias do Estado para promover a agricultura familiar, a prática da agroecologia abre possibilidades para uma maior dinamização produtiva e econômica, aliando processos naturais a estruturas sociais e valorizando atributos peculiares dos territórios locais. Destacaremos, nesse artigo, a prática da agricultura de base ecológica que vem apresentando uma crescente visibilidade na Microrregião de Campina Grande-PB, onde existem sete feiras agroecológicas. Pretendemos discutir como se articulam agricultores, setores sindicais, ONGs e órgãos públicos para a realização das feiras mencionadas, utilizando como perspectiva de análise a teoria do Ator-Rede (TAR), de Bruno Latour. Para tanto, utilizou-se como técnicas de investigação a observação não participante, pesquisa documental e entrevistas semiestruturadas com os feirantes e as distintas representações que apoiam as feiras. Conclui-se que a heterogeneidade com que as redes se apresentam demonstra diferenças quanto ao apoio efetivo à agricultura familiar e às práticas agroecológicas na área da pesquisa em questão.
\end{abstract}

Palavras-chave | Agroecologia; articulações interinstitucionais; Campina Grande; feiras agroecológicas; políticas públicas; teoria ator-rede.

Código JEL | O13; Q18; Q58. 


\title{
INTERINSTITUTIONAL RELATIONS ON AGRO-ECOLOGICAL FAIRS IN THE REGION OF CAMPINA GRANDE-PB
}

\begin{abstract}
Among the State's strategies to promote family farming, the practice of agroecology opens up possibilities for increased production and economic dynamism, combining ecological processes to social structures and giving importance to peculiar attributes of local territories. In this article, it highlights the practice of ecologic based agriculture that has increased visibility in the region of Campina Grande-Paraíba State (Brazil), where there are seven Agro-ecological Fairs. It is discussed how farmers, Labor Unions, NGOs and Government Agencies interact for carrying out the mentioned fairs, using as analytical perspective the Actor-Network Theory (ANT), by Bruno Latour. For that, it was used as investigative techniques the non-interventional observation, documental research and semi-structured interviews with the farmers and the different representatives that support the fairs. It's concluded that the heterogenety on the networks shows differences about the affective support to family agriculture in this research field.
\end{abstract}

Keywords | Actor-network theory; agroecological fairs; agroecology; Campina Grande; interinstitutional relations; public policy.

JEL-Code | O13; Q18; Q58.

\section{ARTICULACIONES INTERINSTITUCIONALES EN LA REALIZACIÓN DE FERIAS AGROECOLÓGICAS EN LA REGIÓN DE CAMPINA GRANDE-PB}

\section{Resumen}

Entre las estrategias del Estado para promover la agricultura familiar, la práctica de la agroecología abre posibilidades para aumentar la producción y el dinamismo económico, la combinación de los procesos naturales y la mejora de las estructuras sociales atributos peculiares de los territorios locales. Resalta en este artículo, la práctica de la agricultura basada ecológicamente ha mostrado una visibilidad cada vez mayor en la microrregión de Campina Grande-Estado de Paraíba (Brasil), donde hay siete ferias agroecológicas. Discutiremos cómo se articulan los agricultores, sindicatos, ONG y agencias gubernamentales para llevar a cabo las ferias mencionadas, utilizando como una perspectiva analítica Teoría del Actor-Red (TAR), Bruno Latour. Por lo tanto, si se utiliza como técnicas de investigación a la observación no participante, la investigación de archivo y entrevistas semi-estructuradas con los proveedores y las diferentes representaciones de apoyo a las ferias. Se concluye que la heterogeneidad con que las redes actuales demuestra diferencias en el apoyo efectivo a la agricultura familiar en el área de investigación de que se trate.

Palabras-clave | Agroecología; articulaciones interinstitucionales; Campina Grande; ferias agroecológicas; políticas públicas; teoría actor-red.

Código JEL | O13; Q18; Q58. 


\section{Introdução}

A agricultura familiar demonstra relevância não só por seu reconhecimento como categoria política, mas por ser propulsora e atuante em políticas governamentais de abrangência nacional, inclusive na perspectiva da agroecologia. A influência da sociedade civil organizada sobre as políticas públicas direcionadas à agricultura familiar ganhou uma nova configuração a partir de 2003, quando, no primeiro mandato do Governo Lula, relações cada vez mais tênues com o Estado acarretaram várias mudanças institucionais e reformulações políticas para o universo dos agricultores familiares e suas organizações. Programas de crédito, de pesquisa, capacitação, assistência técnica e extensão rural e demais políticas voltadas para os agricultores familiares começam a incorporar, ao menos no discurso, proposições elaboradas por movimentos sociais promotores do enfoque alternativo (CAPORAL; PERTENSEN, 2011; LUZZI, 2007). Assim, com o apoio do Estado, atores como ONGs, movimentos sociais, etc., vêm proporcionando a socialização de práticas produtivas sob as bases da agroecologia e da agricultura orgânica nos territórios.

Programas destinados à criação de mercados institucionais, como o Programa de Aquisição de Alimentos (PAA) e a Política Nacional de Alimentação Escolar (PNAE) têm contribuído para ampliação da renda e o fortalecimento do enfoque agroecológico, atraindo um número significativo de agricultores familiares de base ecológica (SCHMITT; GRISA, 2013). No caso destes dois Programas, os mercados institucionais têm beneficiado produtos da agricultura familiar, definindo a obrigatoriedade de no mínimo 30\% dos recursos destes para a compra de gêneros deste setor, privilegiando, sempre que possível, a aquisição de produtos orgânicos e/ou agroecológicos (BRASIL, 2013).

Este incentivo vem reforçando iniciativas de comercialização em circuitos curtos de venda, onde alimentos "ecologicamente corretos" são comprados diretamente dos agricultores familiares ou das associações e cooperativas, que, por conseguinte, vêm fortalecendo redes organizativas em torno da agricultura de base ecológica. Caso emblemático é o das feiras agroecológicas, que trazem alimentos saudáveis advindos da construção de relações de confiança sobre a certificação dos produtos, criando a oportunidade de maior poder de barganha dos produtores e a garantia de escoamento pela venda direta, ao excluir a presença de "atravessadores" (DAROLT, 2013; RAMALHO et al., 2011).

Em geral administradas por parcerias entre o poder público local, associações de produtores e instituições de apoio à agricultura ecológica, os agricultores envolvidos se posicionam politicamente por meio de novas formas de diálogo, edificação de estratégias para comercialização e a interação com os insumos e recursos locais disponíveis. Além disso, as feiras agroecológicas se caracterizam também como espaço de sociabilidade e de troca de experiências, que, além de 
trazerem a valorização de produtos locais, conseguem revalorizar os vínculos sociais entre produtor e consumidor (SANTOS, 2010).

Na Microrregião de Campina Grande, no Estado da Paraíba, um conjunto de relações em rede tem possibilitado a construção de um mercado alternativo, cujo enfoque agroecológico acaba por basear a prática produtiva e o comportamento de distintos atores em torno de sete feiras agroecológicas. Essa Microrregião (Figura 1) possui uma área total de $2.124,8 \mathrm{~km}^{2}$, com população estimada, em 2010, pelo IBGE, em 519.883 habitantes, situada entre as longitudes $35^{\circ} 40^{\prime} 30^{\prime \prime} \mathrm{e}$ $36^{\circ} 14$ '24" $O$, e as latitudes $07^{\circ} 10^{\prime \prime} 15^{\prime \prime}$ e 07 21'28" $S$, com uma área de 2104 $\mathrm{km}^{2}$, densidade de 239,0 hab. $/ \mathrm{km}^{2}$ e altitude de $499 \mathrm{~m}$.

Está dividida em oito municípios - Boa Vista, Campina Grande, Fagundes, Lagoa Seca, Massaranduba, Queimadas, Puxinanã e Serra Redonda -, onde habitam a maior parte dos agricultores que atuam nas feiras agroecológicas analisadas nesse artigo. $\mathrm{Na}$ área pesquisada predominam uma grande quantidade de minifúndios, cujas terras são exploradas por agricultores familiares que sobrevivem da exploração agropecuária através do plantio de hortifrutigranjeiros e da criação de bovinos, suínos e pequenos animais (SOUZA, 2009). 
Figura 1 Mapa da distribuição espacial das feiras agroecológicas na Microrregião de Campina Grande-PB

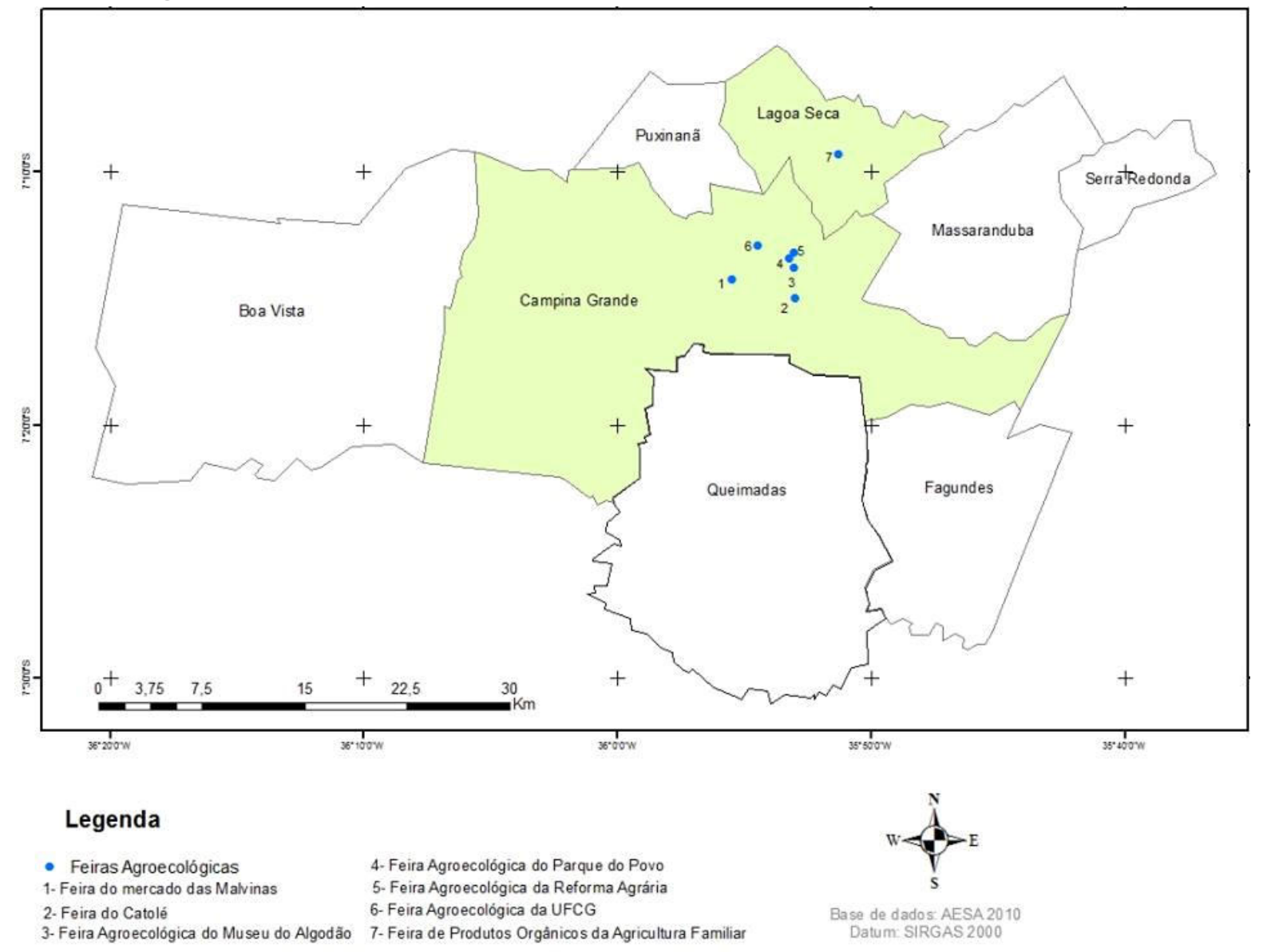

Ao apresentar para a sociedade local a oferta destes produtos oriundos de comunidades e assentamentos rurais da região, estas feiras agroecológicas se instituem apresentando semanalmente uma notória motivação de compra e venda entre comerciantes e consumidores. Em contrapartida, não se sabe efetivamente que atores estão entrelaçados para a ampliação desses espaços de comercialização alternativa.

Assim, este artigo analisa como atua o circuito de políticas, programas e ações voltadas para o desenvolvimento de sete feiras na Microrregião de Campina Grande, utilizando como perspectiva de análise a teoria do Ator-Rede (TAR) de Bruno Latour (2000, 2012). Para este autor, o "social" nada mais é do que elementos de ligação que circulam por malhas em redes. Intenciona-se, então, rearticular os elementos dispostos em conexões seguindo os próprios atores, tentando compreender a existência coletiva do cenário analisado. Assim, buscouse o entendimento de como a rede atua na promoção/incentivo às feiras agroecológicas, rastreando as relações entre os participantes e suas controvérsias para que fosse possível visualizar como as estratégias desempenhadas se 
estruturam na arena pública que possibilita a existência prática e cotidiana destes espaços de comercialização.

\section{Percurso metodológico e esforço de pesquisa}

A coleta de dados foi efetuada a partir da observação não participante, em que foram realizadas 15 visitas sistemáticas às sete feiras agroecológicas, entre os meses de abril e junho de 2015. Nessa etapa foi realizado um acompanhamento de como funcionam as feiras e o cotidiano dos produtores/feirantes com vista a se obter maior familiaridade com a realidade existente nestes espaços. Este momento foi significativo na medida em que foi realizado um mapeamento dos programas e ações locais que são operados pela rede de atores que participam do processo de mediação das políticas governamentais e no fomento direto dado para que as feiras aconteçam.

Logo após, foi realizada uma pesquisa documental, na qual o procedimento de escolha e análise dos documentos nos sites do Ministério do Desenvolvimento Agrário, Ministério do Desenvolvimento Social e Secretaria da Agricultura Familiar (BRASIL, 2013; CONAB, 2007; MDA, 2013) proporcionou um maior nível de conhecimento sobre como se encontram formalizadas as políticas voltadas para a promoção da agroecologia no Brasil, pensando mais centralmente nas políticas que estão criando mercados e dando mais visibilidade aos produtos agroecológicos.

O terceiro momento investigativo consistiu em entrevistas semiestruturadas com 40 feirantes e 5 representantes das instituições responsáveis pela organização das feiras e mediadoras das políticas governamentais que são operadas localmente. Para a obtenção de dados, buscou-se o levantamento de informações sobre os limites e possibilidades enfrentados pelo conjunto de feirantes, bem como a avaliação de como os atores (representantes de ONGs, líderes de associações, agentes governamentais, assessores técnicos) que se colocam como mediadores das políticas participam dos processos de tomada de decisão e direcionamento das ações que dão suporte para estes espaços de comercialização.

As técnicas de pesquisa e a coleta de dados empíricos foram moldadas pela perspectiva das redes sociais, entendidas como estruturas de relação e comunicação expansivas que incluem os mais diversos elementos constituintes da vida social. Redes são constructos de nós interligados, onde todos os nós são necessários para a performance da rede (PAULINO, 2013). Vale salientar que a rede é a unidade e não o nó. Assim, os nós identificados ao longo do texto nada mais são do que o contato, mediação e cooperação entre atores, sejam eles pessoas ou instituições, na formulação das redes promotoras da agricultura ecológica em questão. 
O que temos então é um mundo feito de ligações de mediadores. O mediador cria padrões e protocolos específicos que são transportados para diferentes localidades por meio das redes. Os conteúdos, ao serem transportados são reformulados e reconstituídos nas realidades específicas. A ação social também é delegada a distintos tipos de atores que são capazes de transportá-la através das conexões existentes.

Por fim, o movimento ecológico analisado

se enquadra facilmente nos contornos de uma rede, formada por instituições técnicas, da sociedade civil e de pesquisa, que acabam por legitimar e institucionalizar a fala deste movimento através de um processo de cooptação entre diferentes tipos de organizações (PAULINO, 2013, p. 42).

\section{A rede de atores e a promoção das feiras agroecológicas}

Os desdobramentos da análise das políticas públicas são informados pelas relações sociais construídas e ressignificadas, tanto por meio das diferentes estratégias de ação do Estado, como através de um processo que articula "atores, projetos, instituições, marcos regulatórios, descobertas científicas e desafios postos pela sociedade." (GOMES, 2014, p. 127). Nesse sentido, as políticas públicas não se expressam somente pelas ações dos agentes do Estado, mas abarcam, igualmente, ações advindas de movimentos sociais e instituições não governamentais que as legitimam ou as censuram localmente. Como destaca Arretche (2001, p. 3), "na prática, qualquer política pública é de fato feita pelos agentes encarregados da implementação".

Analisar políticas públicas implica observar os elementos que dão suporte às ações do Estado, sendo compreendido, portanto, como um amplo espaço institucional incumbido de realizar funções de acordo com diversos interesses e dinâmicas que se instituem em torno das redes relacionais em arenas de disputas, tensões, rejeições e acordos. Desse modo, "o Estado não é mais entendido como uma hierarquia pública sempre integrada, senão que ele próprio representa uma rede de organizações relativamente autônomas." (SCHNEIDER, 2005, p. 49).

Como um dos atores, o Estado é representado pelo fluxo simultâneo de associações que se concretizam dentro das múltiplas formas de relacionamento entre os agentes que põem em prática o que está no discurso oficial das políticas (LATOUR, 2012). Para Penna (2014, p. 122), a visão do Estado como uma entidade monolítica "não dá conta de apreender toda a dinâmica envolvida no processo de implementação de políticas públicas, uma vez que não permite a explicitação das redes e conexões presentes ao longo do processo". 
Logo, no intuito de saber como gesta o conjunto de ações que dão suporte as feiras agroecológicas da Microrregião de Campina Grande, é necessário identificar as constantes conexões entre os mediadores que as realizam, revelando um conglomerado de funções que podem influenciar e transformar "o significado ou os elementos que supostamente vinculam" (LATOUR, 2012, p. 65) a sua existência. Ao acompanhar a rede de atores para a promoção das feiras agroecológicas, rastreou-se as constantes associações dos diferentes atores envolvidos no processo de utilização da agroecologia ou agricultura orgânica como estratégia produtiva para a agricultura familiar.

Tal processo tem sido alimentado pela atuação de incontáveis mediadores, formados por elementos humanos e actantes que ao estabelecer conexões heterogêneas entre si conseguem produzir efeitos sobre a rede, modificando-a e sendo modificados por ela simultaneamente (LATOUR, 2000, 2012). A ação dos actantes torna-se visível na medida em que estabelecem a interação entre humanos e mediam a relação destes com outros não-humanos, com o poder de construir iniciativas, medidas, projetos, parâmetros e promover assim transformações no curso da ação de outros agentes. Os mediadores podem ser, por exemplo, os movimentos sociais, ONGs, prefeituras, sindicatos, cooperativas, secretarias, organismos federais, Universidades, dentre outros.

São sete feiras que acontecem em dias variados da semana no período da manhã. Seis delas em pontos distintos da cidade de Campina Grande e uma no município de Lagoa Seca; sendo realizadas, nas quartas-feiras, no Museu do Algodão, no bairro da Estação Velha (Feira Agroecológica da Estação Velha - 22 barracas), e na Universidade Federal de Campina Grande (Feira do Produtor - 32 barracas); nas quintas-feiras, na Praça Clementino Procópio, no Centro (Feira Agroecológica da Reforma Agrária - 13 barracas); nas sextas-feiras, no bairro do Catolé (Feira do Catolé - 5 barracas) e no Parque do Povo (Feira do Produtor - 60 barracas); aos sábados, no bairro das Malvinas (Feira do Produtor - 79 barracas) e no centro do município de Lagoa Seca (Feira de Produtos Orgânicos da Agricultura familiar 10 barracas).

As feiras do município de Lagoa Seca, da Estação Velha e do bairro do Catolé, que vendem apenas produtos orgânicos de base agroecológica, contam com um total de vinte e dois feirantes ativos participantes de ONGs ligadas à agroecologia. Ao comercializar também produtos orgânicos e de base agroecológica, a feira que acontece na Praça Clementino Procópio (Feira Agroecológica da Reforma Agrária) possui um total de treze agricultores ativos de assentamentos do INCRA espalhados pela região. No caso das três Feiras do Produtor (Feira do Parque do Povo, Feira da UFCG e Feira das Malvinas), estas contam com um número significativo de setenta e nove comerciantes que vendem produtos mistos, entre eles, orgânicos. 
Nestas feiras, a presença dos agricultores ou de algum parente no local de venda é exigida, devendo ser vendidos somente alimentos produzidos em regime familiar. Entre os produtos comercializados se destacam i) hortaliças: alface, espinafre, vagem, tomate, cebolinha, coentro, pimentão, cenoura, cebola, beterraba, couve, brócolis; ii) legumes: inhame, feijão verde, mandioca, batatinha, batata doce; iii) frutas diversas; iv) galinhas, e v) alimentos prontos como queijos de coalho, manteiga, bolos, biscoitos, doces caseiros e artefatos artesanais.

Ao se apresentarem como espaços de comercialização diferenciados dos convencionais pela oferta de produtos "limpos", os feirantes recebem acompanhamento que se inicia nos estabelecimentos familiares e vai até $\mathrm{O}$ momento da venda dos produtos, que parte tanto de órgãos federais, quanto de organizações não governamentais de apoio à segurança alimentar e instituições ligadas ao desenvolvimento de projetos de Reforma Agrária. Notoriamente, uma rede de atores atua no sentido de construir semanalmente estes espaços.

Os atores institucionais que dão o suporte direto para que estes espaços aconteçam na Microrregião de Campina Grande se organizam em três redes, conforme o Quadro 1, a seguir.

(continua)

Quadro 1 Instituições que promovem as feiras agroecológicas na Microrregião de Campina Grande-PB

\begin{tabular}{|c|c|c|}
\hline Rede & Feiras agroecológicas & Rede de atores \\
\hline$\frac{\vec{u}}{\vec{U}}$ & $\begin{array}{l}\text { - Feira Agroecológica da Estação } \\
\text { Velha } \\
\text { - Feira Agroecológica do Catolé } \\
\text { - Feira de Produtos Orgânicos da } \\
\text { Agricultura Familiar (Lagoa Seca) }\end{array}$ & $\begin{array}{l}\text { AS-PTA, Polo Sindical da } \\
\text { Borborema, Associação Eco- } \\
\text { Borborema, Prefeitura Municipal } \\
\text { de Campina Grande, Prefeitura } \\
\text { Municipal de Lagoa Seca }\end{array}$ \\
\hline $\begin{array}{l}N \\
\frac{U}{0} \\
\widetilde{\sim}\end{array}$ & $\begin{array}{l}\text { - Feira do Produtor - Parque do } \\
\text { Povo } \\
\text { - Feira do Produtor - UFCG } \\
\text { - Feira do Produtor - Mercado das } \\
\text { Malvinas }\end{array}$ & $\begin{array}{l}\text { EMATER Regional de Campina } \\
\text { Grande, FEAGRO, Associação de } \\
\text { Agronegócio do Compartimento } \\
\text { da Borborema (AACB), Prefeitura } \\
\text { Municipal de Campina Grande }\end{array}$ \\
\hline
\end{tabular}


(conclusão)

\begin{tabular}{|c|c|c|}
\hline 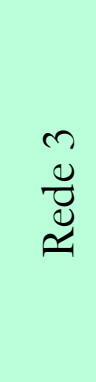 & $\begin{array}{l}\text { - Feira Agroecológica da } \\
\text { Agricultura Familiar }\end{array}$ & $\begin{array}{l}\text { COONAP, INCRA, Associação dos } \\
\text { Produtores do Território da } \\
\text { Borborema; NERA/UEPB; } \\
\text { Prefeitura Municipal, Secretaria de } \\
\text { Agricultura de Campina Grande, } \\
\text { Secretaria de Infraestrutura e de } \\
\text { Serviços Urbanos (SESUMA) }\end{array}$ \\
\hline
\end{tabular}

Fonte: Elaborado pelos autores.

Neste cenário, a primeira rede (Rede 1), responsável pela organização das feiras de Lagoa Seca, da Estação Velha e do bairro Catolé, é composta primordialmente por entidades da sociedade civil, que desde a segunda metade da década de 1990 realizam um trabalho em conjunto na perspectiva de desenvolver experiências sob enfoque agroecológico nas localidades que compõem o Agreste Paraibano. São participantes a Assessoria e Serviços a Projetos em Agricultura Alternativa (ASPTA), o Polo Sindical da Borborema ${ }^{1}$, a Associação EcoBorborema ${ }^{2}$, contando ainda com o esforço integrado do poder público local com as prefeituras de Campina Grande e Lagoa Seca, que cedem os espaços para que as feiras ocorram.

Com a constatação de que muitas famílias estavam sendo intoxicadas com o uso de agrotóxicos, gradativamente a AS-PTA, uma associação de direito civil sem fins lucrativos que atua para o fortalecimento do enfoque agroecológico na agricultura familiar, iniciou um trabalho de conscientização e formação sobre as vantagens do cultivo com técnicas diferenciadas, formando um corpo de agricultores experimentadores. Com o "Programa Paraíba" desta ONG localizada do município de Esperança, junto aos agricultores de comunidades rurais do Polo Sindical da Borborema, estas organizações passam a atuar em projetos de desenvolvimento rural alicerçados nos princípios da agroecologia.

A partir da atuação da AS-PTA, a questão agroecológica passa a fazer parte das demandas assumidas por um grande número de agricultores e o Polo Sindical da Borborema, que antes somente se organizava em torno de causas trabalhistas, se concretiza como um espaço promotor de capacidades locais e referência em termos de construção de um território agroecológico no Estado da Paraíba. Para Veja e Jalil (2013, p. 48), o Polo Sindical da Borborema "se constitui como um patrimônio, tanto material quanto intangível, das diversas comunidades", ao se

\footnotetext{
1 Trata-se de uma entidade representativa formada por 16 sindicatos de trabalhadoras e trabalhadores rurais (STRs) e aproximadamente cento e cinquenta associações comunitárias do interior paraibano.

${ }^{2}$ Organização regional de apoio e assistência a agricultores ecológicos.
} 
revelar como uma importante rede organizativa tanto na preservação e geração de conhecimentos em agroecologia quanto com sua forte atuação na esfera pública.

Com mais de 100 sócios, ligados direta ou indiretamente às feiras agroecológicas, a Associação EcoBorborema, uma entidade jurídica localizada na sede da AS-PTA, é a organização responsável por direcionar o funcionamento destas feiras, desenvolvendo um trabalho direto com os agricultores que vai desde a produção até a comercialização nos locais de venda. Organizada em comissões temáticas, é também a Associação EcoBorborema quem se coloca no papel de mediadora, representando os feirantes em programas e projetos do governo federal e mantendo contatos frequentes com os poderes públicos locais.

No que concerne à segunda rede (Rede 2) de instituições responsável pelas três "Feiras do Produtor" que comercializam produtos mistos, esta é composta pela Empresa de Assistência Técnica e Extensão Rural Regional de Campina Grande (EMATER), a Associação de Agronegócio do Compartimento da Borborema (FEAGRO/AACB), bem como a Prefeitura Municipal de Campina Grande, que cede dois espaços, um no centro da cidade e o outro em um Mercado no bairro das Malvinas. Outra participante nesta rede é a Universidade Federal de Campina Grande que também cede um espaço no pátio da Universidade para que a feira seja realizada.

Nesta rede, a participação da EMATER tem um papel fundamental, já que desde os anos 1990 o escritório local media a relação entre as ações do governo federal tais como, o acesso ao crédito e assistência técnica - e os agricultores familiares da Mesorregião da Borborema. No âmbito das três "Feiras do Produtor" (Parque do Povo, UFCG e Mercado das Malvinas), a atuação da EMATER foi direcionada ao combate à presença dos atravessadores, possibilitando ao agricultor familiar obter maior retorno financeiro com a comercialização de produtos alternativos aos convencionais.

Dada à necessidade de uma entidade que gerisse as já consolidadas três "Feiras do Produtor", a Associação de Agronegócio do Compartimento da Borborema (AACB/FEAGRO) surge como uma entidade de representação política dos agricultores envolvidos. A AACB/FEAGRO nasce com o objetivo institucional de organizar e discutir os rumos das feiras, evitando a entrada de produtos trazidos de fora e garantindo a permanência dos agricultores agroecológicos nesses espaços de comercialização.

A terceira rede (Rede 3) é composta pelo Instituto Nacional de Colonização e Reforma Agrária (INCRA), a Cooperativa de Apoio de Trabalho Múltiplo de Apoio às Organizações de Auto Promoção (COONAP), o Instituto de Assessoria à Cidadania e ao Desenvolvimento Local Sustentável (IDS), o Núcleo de Extensão Rural e Pesquisa Agroecológica (NERA) da Universidade Estadual da Paraíba (UEPB), e a Prefeitura Municipal de Campina Grande, através da Secretaria de 
Agricultura e a Secretaria de Infraestrutura e de Serviços Urbanos e Meio Ambiente (SESUMA).

Nesta articulação, a IDS, que tem como principal objetivo divulgar produtos tradicionais em cooperação com associações locais, possibilitou que o Ministério do Desenvolvimento Agrário disponibilizasse recursos financeiros para o INCRA (instituição que atende 31 assentamentos de Reforma Agrária). Através destes recursos, o INCRA passa a contratar os serviços de assistência técnica, social e ambiental da Cooperativa de Trabalho Múltiplo de Apoio às Organizações de Autopromoção (COONAP) que, por sua vez, vem atendendo inúmeras famílias assentadas no oferecimento de vários serviços de cidadania e direitos sociais.

Para ampliar a capacitação dos agricultores em agroecologia, a COONAP colabora com o processo de formação dos educandos em agroecologia por meio do Núcleo de Extensão Rural e Pesquisa Agroecológica (NERA), localizado no Campus II da Universidade Estadual da Paraíba em Lagoa Seca. A participação do NERA visa integrar ações educativas do Curso de Agroecologia da UEPB, trabalhando com agricultores experimentadores de base familiar e suas organizações nos assentamentos.

Além destas organizações que promovem a feira, a Prefeitura de Campina Grande cede um espaço em uma praça central do município, atuando também por meio de duas instâncias, a Secretaria de Agricultura, que organiza e é responsável pela manutenção dos locais de venda, e a Secretaria de Infraestrutura e de Serviços Urbano e Meio Ambiente (SESUMA), que realiza um trabalho de logística e divulgação em meios midiáticos, tais quais internet e rádio.

\section{Conexões e controvérsias: as feiras agroecológicas na Microrregião de Campina Grande}

\section{As feiras agroecológicas do Polo Sindical da Borborema}

Em um processo de mais de três anos de mobilização em torno de uma alternativa de escoamento para os produtos agroecológicos que eram vendidos para a CEASA de Campina Grande, surge a primeira feira agroecológica da Microrregião: a AS-PTA, ao disponibilizar apoio técnico para a formação agroecológica e produção orgânica através de um projeto experimental que foi encaminhado à Prefeitura de Lagoa Seca, dá origem a um evento denominando "Natal Sem Veneno", fato que ocorreu no final do ano de 2001. A feira foi realizada com uma estrutura precária, com poucas barracas. Todavia, a mesma apresenta um número significativo de consumidores, fazendo com que, no ano posterior, a Prefeitura de Lagoa Seca cedesse um espaço específico no Mercado Central do município. 
Naquele período, a atuação da AS-PTA dentro do Polo Sindical esteve focada na articulação de profissionais para um trabalho de divulgação para a população em geral, com panfletagem e inserções em rádios locais, realizando palestras e promovendo viagens para que os feirantes conhecessem o funcionamento de feiras agroecológicas existentes nas cidades de João Pessoa e Recife.

No intuito de expandir para outros locais de comercialização, a sede da AS-PTA, no município de Esperança, passa a ser utilizada como local para oferecer cursos e oficinas aos agricultores que estavam se organizando em torno dos métodos de certificação participativa, manuseio e qualidade dos produtos a serem vendidos. Ainda sem a existência da Associação EcoBorborema, a AS-PTA, junto ao Polo Sindical, mobilizou projetos de apoio financeiro, encaminhando-os a políticos locais que auxiliaram na compra de barracas, lonas, balanças, batas e demais artefatos. Com uma estrutura básica em um mercado restrito em Lagoa Seca e o descrédito da população local sobre os produtos diferenciados, surge a ideia de expandir a feira para um município de maior visibilidade.

Desse modo, a AS-PTA encaminhou um projeto para realização de uma "Feira Regional" que foi levado à Prefeitura de Campina Grande, fazendo com que, após um ano, a Prefeitura cedesse o espaço da área interna da Estação Velha para que ali os agricultores pudessem comercializar seus produtos às quartas-feiras. Com o espaço interno do Museu do Algodão cedido pela Prefeitura Municipal de Campina Grande, a Feira Agroecológica da Estação Velha teve início no ano de 2005, acontecendo semanalmente às quartas feiras com um número maior de feirantes.

Para a instalação dessa feira, os recursos financeiros vieram tanto de um projeto encaminhado para o Governo Federal, que disponibilizou parte da infraestrutura, quanto de projetos da própria AS-PTA, se utilizando de um Fundo Rotativo Solidário. Nesse mesmo ano, dada a necessidade de uma entidade capaz de convergir com as ações da AS-PTA e o Polo Sindical, é criada Associação EcoBorborema, como uma entidade representativa e articuladora dos comerciantes envolvidos, gerando e compartilhando as informações necessárias para o funcionamento das feiras já existentes.

Com a visibilidade e consolidação destes espaços, a Associação EcoBorborema é quem faz o acompanhamento com os agricultores, desde o plantio até a distribuição e comercialização dos produtos, com um corpo de profissionais que fiscalizam o que está sendo produzido. Para gerir o funcionamento das feiras, a EcoBorborema estabelece canais de comunicação da AS-PTA do Polo Sindical com os agentes do poder público local, a exemplo de prefeitos, vereadores e outros atores, com vistas a obtenção de mais espaços para que outros agricultores do Polo Sindical passassem a comercializar seus produtos.

No ano de 2007, a Associação realizou um diálogo com uma consumidora, proprietária de uma escola de ensino fundamental no Bairro do Catolé em 
Campina Grande (Centro Educacional Moderno - CEM), que, por sua vez, faz um convite para que fosse realizada uma feira experimental em frente àquela instituição. Para tanto, inicia-se um trabalho de divulgação entre pais e alunos sobre os benefícios de uma alimentação mais saudável e livre de venenos no bairro, por intermédio de um projeto pedagógico realizado por professores, coordenadores e a própria direção.

Após a realização de uma reunião com os agricultores na sede da AS-PTA, para informar a disponibilidade de um novo espaço em Campina Grande, a Associação EcoBorborema definiu um dia diferente para a utilização do espaço: as sextasfeiras. Logo, com um número frequente de consumidores moradores do bairro se consolida a terceira feira agroecológica da Microrregião (Feira Agroecológica do Catolé) em frente desta instituição, na qual os mesmos comerciantes, atuantes nas outras duas feiras, passam a ter mais um espaço na cidade.

No período inicial, os feirantes pagavam os transportes das barracas e dos produtos. Os fretes eram realizados por caminhonetes de terceiros que se encarregavam do serviço. Com a fidelização de consumidores no decorrer dos anos, os comerciantes passam a contribuir com uma taxa de $\mathrm{R} \$ 2,00$ por dia trabalhado à Associação EcoBorborema, que serve para o aluguel de uma casa nas imediações das feiras tanto em Campina Grande como em Lagoa Seca e o pagamento de um funcionário terceirizado para que faça o transporte, montagem e desmontagem das barracas.

Para gerir a organização dos produtores, a cada dois meses é realizada a assembleia da Associação EcoBorborema, da qual participam todos os associados e integrantes das comissões. Além disso, a EcoBorborema realiza mensalmente uma reunião para tratar de questões mais específicas como avaliação de resultados da feira, planejamento da produção, contabilidade, projetos de transporte, entre outras.

Com um número restrito de feirantes, todos os participantes ativos devem ser agricultores agroecológicos, e, assim, um trabalho de inspeção é realizado pela Associação EcoBorborema para que nenhum outro agricultor que não esteja filiado ou que não produza sob os princípios da agroecologia adentrem os espaços. Entre as técnicas agroecológicas utilizadas se apresentam a rotação de culturas, adubação verde, compostagem, aplicação de biofertilizantes, entre outras. No mais, para a entrada ou permanência nas feiras, os agricultores comerciantes devem manter a plantação e os produtos sempre limpos e apresentáveis, com um bom acondicionamento destes, e para a venda devem se utilizar de sacolas plásticas novas.

Para a confiabilidade do que está sendo produzido nestas feiras, a EcoBorborema incentiva a prática da certificação participativa, que consiste em visitas de intercâmbio para que haja uma fiscalização e acompanhamento mútuo, objetivando a retirada de dúvidas e geração de novos conhecimentos entre os 
agricultores. Ademais, com um trabalho em conjunto com AS-PTA, periodicamente a Associação organiza visitas de consumidores de Campina Grande às propriedades para que estes conheçam os métodos de produção.

De acordo com os feirantes entrevistados, o fato de serem participantes da associação EcoBorborema vem fortalecendo o relacionamento entre os produtores por meio da efetivação de atividades conjuntas e integradas. No que diz respeito a políticas governamentais como o Programa de Aquisição de Alimentos (PAA), foi por meio da atuação na feira que desde o ano de 2009 todos os feirantes envolvidos têm acesso à política como um incentivo para produção e comercialização. Para o acesso dos agricultores ao Programa, a EcoBorborema realiza um levantamento de produção com as famílias, direcionando o quê e como cada agricultor vai produzir durante o período estipulado pela política.

$\mathrm{O}$ acesso ao PAA permitiu a parceria com a CONAB e o Programa Mesa Brasil do SESC de Campina Grande. Esse arranjo permite que alguns agricultores/feirantes comercializem seus produtos, ficando a cargo do próprio SESC a distribuição gratuita dos produtos às instituições atendidas pelo seu programa social. Desde 2014, alguns agricultores também têm acesso ao PNAE de Lagoa Seca, em que a administração de projetos da EcoBorborema auxilia os agricultores, organizando um cronograma de produção de acordo com a chamada pública realizada pela prefeitura. A compra dos alimentos que são destinados a suprir as necessidades das escolas do município é realizada através de chamadas públicas nas quais são definidos os produtos, as quantidades e os preços que serão pagos.

\section{As feiras do produtor organizadas pela EMATER}

Através do trabalho que já vinha sendo realizado pela equipe da EMATER Regional de Campina Grande, constatou-se que os agricultores encontravam dificuldades para comercializar os produtos, especialmente pelo receio de serem enganados pelos atravessadores que compravam seus produtos e não pagavam, situação já experimentada anteriormente. A EMATER, por sua vez, realizou um levantamento dos agricultores que queriam comercializar, com o intuito de agregar valor aos produtos locais por meio da venda direta ao consumidor.

A EMATER passa então a fazer contato com a Prefeitura Municipal de Campina Grande, que, após alguns meses de negociação, cede, no ano de 1996, o espaço da pirâmide do Parque Ronaldo Cunha Lima (popularmente conhecido como Parque do Povo) para que a feira fosse realizada semanalmente. Em termos de infraestrutura, os recursos para a instalação das barracas vieram tanto do governo do Estado da Paraíba, quanto da Prefeitura Municipal de Campina Grande, que disponibilizou lonas, batas e etc. 
No início, muitos agricultores enfrentaram dificuldades para transportar os produtos até Campina Grande, ficando na dependência das prefeituras de seus respectivos municípios a responsabilidade dos custos com alimentação e transporte. No decorrer do primeiro ano, o espaço até então denominado Feira da Agropecuária ganha mais visibilidade em nível regional com o nome de Feira de Utilidade Pública, advindo da Câmara Municipal de Vereadores de Campina Grande.

Diante do expressivo número de agricultores que queriam comercializar, os técnicos da EMATER sentiram a necessidade de ampliar a comercialização para mais um dia da semana e em um novo espaço, fazendo a intermediação junto a professores da Universidade Federal de Campina Grande. A EMATER elaborou um projeto que foi encaminhado para a Prefeitura da UFCG, que, no ano de 1998, cedeu espaço no pátio da instituição para que fosse realizada a segunda "Feira do Produtor" da Microrregião, conhecida como a Feira da UFCG, que acontece semanalmente às quartas-feiras.

No ano de 1999, é a Prefeitura Municipal de Campina Grande que estabelece contatos com a EMATER para levar os comerciantes das duas feiras - do Parque do Povo e da UFCG - para o Mercado do bairro das Malvinas, que na época funcionava precariamente. Dessa conexão, os feirantes passam a comercializar aos sábados na tentativa de ganhar mais um espaço de mercado entre consumidores de uma área periférica do município de Campina Grande.

Nos primeiros anos das três Feiras do Produtor, a EMATER manteve contatos com o SINE e o SEBRAE de Campina Grande para que fossem realizados cursos de capacitação em "Qualidade", "Agregação de Valor aos Produtos" e "Comercializar Entendendo de Competitividade". Ao coordenar as feiras, é também a EMATER quem controla a entrada dos agricultores nestas, fiscalizando se há vagas e se o produto oferecido é viável para ser comercializado naquele espaço.

Para prover a organização das feiras, foi criado pela EMATER, junto aos agricultores, a Associação de Agronegócio do Compartimento da Borborema (AACB/FEAGRO), no ano 2000, com intuito de fortalecer a comercialização dos produtores sem a existência de nenhum outro feirante não associado e de representar um espaço democrático tanto para resolver problemas, quanto para ampliar as condições de acesso às políticas públicas.

Segundo a EMATER, não se tinha a noção, no início das feiras, do que elas se tornariam espaços apropriados para a comercialização de produtos orgânicos. Desse modo, com a proposta de ganhar espaço de mercado, bem como a exigência dos consumidores por produtos "limpos", as feiras que até então eram somente para limar a figura do atravessador na comercialização de produtos convencionais, a partir de 2004 passam a também comercializar alimentos orgânicos. 
O auxilio dos extensionistas envolvidos, que iniciam um trabalho de estímulo a novas metodologias, notadamente com o incentivo da Política de ATER para a conversão da base produtiva dos agricultores atendidos, fez com que muitos feirantes passassem a aderir à produção sem agrotóxicos. Estes viram na produção orgânica uma forma de melhor competir no mercado, se utilizando das técnicas e condições climáticas disponíveis em seus respectivos municípios.

Para o beneficiamento da produção sem o uso de agrotóxicos, a EMATER vem realizando projetos de pesquisa e cursos de capacitação sobre práticas de manejo agroecológico por intermédio da Agência de Vigilância Sanitária (AGEVISA). Com estes cursos, foram disseminados conhecimentos sobre boas práticas de higiene pessoal, importância da limpeza do local das feiras, manipulação de produtos, adequação para um melhor transporte de produtos agrícolas, dentre outros.

Todavia, com o passar dos anos, a prática da agroecologia e da agricultura orgânica vêm sendo colocadas em segundo plano, ao passo que o número de agricultores nas feiras foi se expandindo, fazendo com que a EMATER tenha dificuldades para fazer o acompanhamento. Atualmente, a EMATER restringe-se a visitas sem nenhum acompanhamento efetivo sobre a produção sem agrotóxicos. Com relação à fiscalização e análise das propriedades, a participação da EMATER foi enfraquecendo, observando-se que, na prática, as normas estabelecidas não são fielmente cumpridas.

Em muitos casos, o controle da produção e a garantia de qualidade dos produtos não são realizados com o devido rigor pela instituição, fazendo com que cada produtor aja de forma independente, ficando a cargo destes a responsabilidade pelos processos de certificação. A atuação da EMATER junto aos agricultores passou a ser estritamente voltada à organização e comercialização dos produtos nas feiras, fazendo com que o grupo de agricultores/feirantes se tornasse heterogêneo, existindo produtores orgânicos (em sua minoria) e produtos convencionais.

No que concerne à entidade política representativa dos agricultores associados, a AACB/FEAGRO vem perdendo seu poder político institucional não realizando mais suas funções como nos primeiros anos. Além de não se discutir mais temas de interesse comum, como os preços das mercadorias, a qualidade do produto e a produção sem venenos, a Associação se resume ao recolhimento de uma taxa de $\mathrm{R} \$ 5,00$ de cada feirante, por feira, para o deslocamento, montagem e desmontagem das barracas, cujo serviço a EMATER terceiriza.

Para os feirantes entrevistados, a falta de organização e o enfraquecimento de decisão democrática em relação à autonomia política da AACB/FEAGRO têm feito com que o grande número de comerciantes não sinta mais credibilidade na Associação, sendo que muitos destes, residentes em distintas localidades, só se encontram nos dias das feiras. Os feirantes participantes agem de forma individual 
e se relacionam com a EMATER apenas quando há alguma dúvida referente à atividade produtiva. Segundo eles, no caso da EMATER, o apoio dado no decorrer dos anos proporcionou a estes inúmeras melhorias em suas propriedades, fazendo com que nos dias atuais possuam autonomia financeira para trazer seus produtos e tenha acesso às políticas do governo.

No que concerne às políticas governamentais, todos os agricultores envolvidos são cadastrados no PRONAF grupo B ou C, ressaltando que a atuação dos extensionistas da EMATER para o acesso ao Programa se restringe a realizar o cadastramento dos feirantes para emissão de DAPs, fazendo o diagnóstico nas unidades de produção e elaborando os projetos de venda para o Programa de Aquisição de Alimentos e a Política Nacional de Alimentação Escolar nos respectivos munícipios dos agricultores/feirantes.

\section{Feira agroecológica da reforma agrária}

A mais recente feira agroecológica da Microrregião de Campina Grande teve início no dia 9 de outubro de 2014, tendo como principal idealizador o corpo técnico da Cooperativa de Trabalho Múltiplo de Apoio às Organizações de Autopromoção (COONAP), que já atua em projetos voltados à agroecologia desde o ano de 2011, mobilizando discussões dentro da Associação dos Assentados da Reforma Agrária do INCRA para a criação de uma feira que concretizasse a venda direta da produção com a retirada dos atravessadores.

Assim como nas demais feiras agroecológicas, a ideia surgiu em virtude de muitos assentados sentirem dificuldades com relação ao escoamento do que estava sendo produzido, e, sendo assim, a COONAP prestadora de serviços de assistência técnica para o INCRA, elaborou um projeto que foi encaminhado à Secretaria Municipal de Agricultura de Campina Grande, que após um ano de negociação escolheu um ponto estratégico que permitisse boa visibilidade para instalação da feira.

Com a liberação de recursos financeiros do INCRA, oriunda da intermediação do Instituto de Desenvolvimento Social (IDS) com o Ministério do Desenvolvimento Agrário, a COONAP adquiriu toda a infraestrutura da feira, como barracas, lonas, batas, balanças e etc., à espera de um espaço em Campina Grande para que os agricultores dos assentamentos pudessem trazer seus produtos para a venda. Nesse contexto, foi cedido o espaço da Praça Clementino Procópio no centro da cidade às quintas feiras.

Para que a população tomasse conhecimento de mais uma feira agroecológica, o espaço foi inaugurado com bastante divulgação. Esse trabalho foi feito pela Secretaria de Serviços Urbanos e Meio Ambiente (SESUMA) e pela Secretaria de Agricultura, que convidaram a imprensa (TV, Rádio e mídias virtuais) para cobrir a 
solenidade que contou com um grande número de representações políticas locais. Ademais, foi feito um trabalho de logística com a colagem de cartazes e entrega de panfletos nos semáforos sobre a importância de uma alimentação livre de agrotóxicos.

Por meio do Programa de Assessoria Técnica, Social e Ambiental à Reforma Agrária (ATES), criado em 2003, a COONAP é quem faz o acompanhamento nos assentamentos para que todos os comerciantes produzam de maneira totalmente orgânica, que tenham formação em agroecologia, e que não vendam seus produtos para atravessadores. $\mathrm{Na}$ feira, não é permitida a existência de produtos oriundos de outras localidades, havendo uma fiscalização rigorosa feita tanto por técnicos da COONAP, quanto pelos próprios agricultores/feirantes.

Para estimular a organização dos agricultores/feirantes a Cooperativa estabelece a comunicação com o INCRA para prestar contas do que está sendo realizado, de como os agricultores estão administrando a produção (manejo e qualidade dos produtos), do que está sendo produzido e etc. No que diz respeito à instalação e manutenção do espaço utilizado, funcionários da Secretaria de Agricultura de Campina Grande depositam e recolhem as barracas no final de cada feira e os próprios comerciantes participam da montagem e desmontagem das mesmas. $\mathrm{O}$ transporte dos produtos é realizado pelos comerciantes, alguns possuem veículos próprios e outros fretam caminhonetes de terceiros.

Além do acompanhamento semanal dos agentes de ATES da COONAP nas lavouras, mensalmente todos os assentados dispõem de cursos de capacitação, profissionalização em artesanato e momentos educativos que envolvem oficinas e palestras. Ainda para os feirantes, vem sendo disponibilizados cursos de manejo com aplicação de adubos orgânicos, alimentação alternativa, horticultura, fabricação de queijos, doces caseiros e derivados do leite, entre outros.

Nesse âmbito, a parceria da COONAP com o Núcleo de Extensão Rural Agroecológica (NERA), da Universidade Estadual da Paraíba, vem atuando por meio de projetos pedagógicos de formação prática de manejos sustentáveis, oferecendo também a formação teórica nos termos da transição agroecológica, com o foco principal nas mulheres e nos jovens. Outra ação de apoio à feira Agroecológica da Reforma Agrária é o "Programa Terra Sol", executado pela COONAP, que trabalha na gestão de agroindústrias e atividades não agrícolas, realizando pesquisas de mercado e atuando na divulgação da venda de produtos agroecológicos, como o artesanato que é levado para a feira.

Conforme assinalam os feirantes entrevistados, a atuação da COONAP dentro do INCRA vem melhorando a vida dos assentados, pois agora estão se profissionalizando, tendo uma renda extra e a garantia da comercialização de seus produtos. Segundo eles, tem havido uma diminuição do número de feirantes devido ao período da estiagem, fazendo com que não se tenha produtos para trazer para a feira: todavia, todos os que iniciaram, desde o período de sua 
instalação, participam ativamente da Associação dos Assentados da Reforma Agrária.

Nesta Associação, os feirantes e assentados participam diretamente de reuniões com os técnicos de ATES, representantes do INCRA e demais dirigentes das instituições, tal qual a Secretaria de Agricultura de Campina Grande, com o intuito de discutir tanto os rumos que serão tomados para continuarem trazendo seus produtos para as feiras, quanto para que possam ser representados politicamente em suas demandas.

\section{Considerações finais}

Tendo em vista os aspectos analisados, as três redes, cada qual com sua especificidade, mostram que o processo coletivo que está sendo fomentado é a força motriz para impulsionar as ações que vêm sendo desenvolvidas e implementadas localmente, com vistas a dinamizar a economia dos agricultores familiares, mais especificamente a comercialização de produtos agroecológicos e orgânicos no interior do Estado da Paraíba. Assim, as conexões entre feirantes, técnicos e instituições vêm construindo uma alternativa para a agricultura camponesa através da venda direta aos consumidores. Nesse contexto, o surgimento de novas relações sociais, culturais e econômicas estruturadas sobre as bases da agroecologia na Microrregião de Campina Grande sinalizam para uma dinâmica produtiva, para a criação de possibilidades de autonomia financeira dos agricultores que participam das feiras agroecológicas, e, finalmente, para a revalorização de produtos locais.

Portanto, a heterogeneidade com que as redes se apresentam, sendo mais ou menos articuladas e/ou organizadas, demonstram diferentes níveis de eficácia quanto ao escoamento de alimentos e de apoio à agricultura familiar na localidade pesquisada. Além da disseminação de experiências práticas em agroecologia, as diferenças com que as redes de atores mediam as ações que fomentam as feiras têm promovido mudanças significativas na medida em que ampliam as possibilidades de empoderamento dos agricultores/feirantes por meio do acesso ao mercado e às redes sociotécnicas, aumentando o capital de conhecimentos e contatos diversos.

Através do diagnóstico realizado, a participação semanal nas feiras agroecológicas tem sido responsável pela melhoria de vida dos agricultores/feirantes. Conforme relatos dos feirantes entrevistados, a atuação de cada rede analisada tem produzido relações de confiança que fazem com que os agricultores as reconheçam como essenciais na existência das feiras, a exemplo das várias formas de assessoria que vêm sendo disponibilizadas para a obtenção de retornos financeiros e para a organização dos agricultores/feirantes. Contudo, problemas são identificados 
pelos feirantes para o desenvolvimento desses espaços de comercialização, entre estes figura a produção descontínua pelas recorrentes estiagens, dificuldades na divulgação para um maior nível de conhecimento do consumo sem agrotóxicos, assim como a falta de veículos adequados para o transporte dos produtos.

De modo geral, a comercialização e a rentabilidade econômica nestas feiras agroecológicas encontram-se em desvantagem em relação ao mercado agrícola padrão. Para maior nível de autonomia econômica dos agricultores atuantes, as ações de beneficiamento às feiras devem ser mais efetivas, desde $\mathrm{o}$ acompanhamento nas propriedades, com forte emprego de mão de obra. Para o incremento e distribuição de renda, o incentivo à certificação participativa e à diversificação produtiva deve se adequar ao desenvolvimento de tecnologias mais sustentáveis, no intuito de prover uma maior qualidade dos produtos aos consumidores. Uma maior participação nos processos decisórios e efetivo compartilhamento de informações, certamente, podem proporcionar o estabelecimento de relações mais estáveis no que concerne à organização dos feirantes.

Enfim, para o momento é possível perceber que, dada à ampliação quantitativa das feiras agroecológicas no decorrer dos anos, as redes têm auxiliado na garantia de escoamento da produção, e, na maior parte dos casos, mediado o acesso dos agricultores às políticas do Estado. Apesar das dificuldades do enfoque agroecológico se desenvolver, principalmente no que envolve a sua luta por legitimidade em detrimento do agronegócio convencional, as redes de atores estão ativas e vem proporcionando uma nova cultura de comercialização e consumo, mesmo que nestas feiras ainda existam inúmeros limites a serem ultrapassados.

\section{Referências}

ARRETCHE, M. T. S. Uma contribuição para fazermos avaliações menos ingênuas. In: BARREIRA, M. C. R. N.; CARVALHO. M. C. B. (Orgs.). Tendências e perspectivas na avaliação de políticas e programas sociais. São Paulo, IEE/PUC-SP, 2001.

BRASIL. Plano Nacional de Agroecologia e Produção Orgânica. Ministério do Desenvolvimento Agrário. Brasília, 2013. Disponível em: http://www.mda.gov.br. Acesso em: 22 abr. 2015.

CAPORAL, F. R.; PERTERSON, P. Agroecologia e políticas públicas na América Latina: o caso do Brasil. Agroecologia, v. 6, p. 63-73, 2011. 
DAROLT, M. R. Circuitos curtos de comercialização de alimentos ecológicos: reconectando produtores e consumidores. In: NIEDERLE, Paulo André; ALMEIDA, Luciano de; VEZZANI, Fabiane Machado (Org.). Agroecologia: práticas, mercados e políticas para uma nova agricultura. 1. ed. Curitiba: Kairós, p. 139-170, 2013.

GOMES, R. A. Modos e objetivação de programas públicos: o PAA em foco. In: NEVES, Delma Pessanha; GOMES, Ramonildes A.; LEAL, Pedro Fonseca. (Org.). Quadros e programas institucionais em políticas públicas. Campina Grande: EDUEPB, 2014. p. 127-133.

GRISA, C.; SCHMITT, C.; MATTEI, L. ; MALUF, R. ; Leite, S. Contribuições do Programa de Aquisição de Alimentos à segurança alimentar e nutricional e a criação de mercados para a agricultura familiar. Revista Agriculturas (Impresso), v. 8, p. 34-41, 2011.

IBGE. Instituto Brasileiro de Geografia e Estatística. Divisão regional do Brasil em mesorregiões e microrregiões geográficas, v. 1, Rio de Janeiro: IBGE; 1990.

LANDINI, F. P. Problemas enfrentados por extensionistas rurais brasileiros e sua relação com suas concepções de extensão rural. Ciência Rural, Santa Maria, v. 45, n. 2, p. 371-377, fev., 2015.

LATOUR, B. Ciência em ação: como seguir cientistas e engenheiros agora. São Paulo: UNESP, 2000.

. Reagregando o social: uma introdução à teoria do ator-rede. Salvador: Edufba, 2012; Bauru/SP: Edusc, 2012.

LUZZI, Nilsa. O debate agroecológico no Brasil: uma construção a partir de diferentes atores. 2007. 182 p. Tese (Doutorado em Desenvolvimento, Agricultura e Sociedade) - Universidade Federal Rural do Rio de Janeiro, Instituto de Ciências Humanas e Sociais, Curso de Pós-Graduação em Desenvolvimento, Agricultura e Sociedade, Rio de Janeiro, UFRRJ, 2007.

PAULINO, Jonatta S. Modernidade e ciência: tensões do discurso agroecológico. 2013. Dissertação (Mestrado em Ciências Sociais) - Programa de Pós-Graduação da Universidade Federal de Campina Grande, UFCG, Brasil, 2013. 
PENNA, Camila . Incra como Ator-Rede: estudo das relações entre os servidores da SR-27. In: NEVES; Delma; GOMES; Ramonildes; LEAL, Pedro. (Org.). Quadros e programas institucionais em políticas públicas. $21 \mathrm{ed}$. Campina Grande: EDUEPB, 2014, p. 105-127.

RAMALHO, A. M. C.; SANTOS, J. G.; SILVA, S. S. F. Reconstruindo um Cenário Socioambiental e as Práticas de Consumo: as Feiras Agroecológicas do Agreste da Borborema - PB. In: SBS - Sociedade Brasileira de Sociologia. Anais... Curitiba, 2011.

RAMOS, N. L. As redes de atores no semiárido paraibano: trilhas e caminhos da ASA. 2009. Tese (Doutorado em Sociologia) - Pós-Graduação em Sociologia, Universidade Federal da Paraíba, UFPB, 2009.

SANTOS, T. A. Agroecologia como prática social: feiras agroecológicas e insubordinação camponesa na Paraíba (Dissertação) - Universidade de São Paulo, USP, Brasil, 2010.

SCHMITT, C.; GRISA, C. Agroecologia, mercados e políticas públicas: uma análise a partir dos instrumentos de ação governamental. In: NIEDERLE, Paulo André; ALMEIDA, Luciano de; VEZZANI, Fabiane Machado. (Org.). Agroecologia: práticas, mercados e políticas para uma nova agricultura. 1ed. Curitiba: Kairós, 2013. p. 215-265.

SCHNEIDER, V. Redes de Políticas Públicas e a Condução de Sociedades Complexas. Civitas, Porto Alegre v. 5 n. 1 jan./jun., p. 29-58, 2005.

SOUZA, G. M. C. Buscando construir sustentabilidade: o caso dos agricultores familiares do município de Alagoa Nova-PB, participantes da feira agropecuária de Campina Grande-PB/Feagro/CG. Dissertação (Mestrado em Recursos Naturais) - Pós Graduação em Recursos Naturais, Universidade Federal de Campina Grande, UFCG, Brasil, 2009.

VEGA, G. C.; JALIL, L. M. Rede de Assistência Técnica e Extensão Rural da Sociedade Civil Nordeste, Rede ATER-Nordeste. 2013. (Relatório de pesquisa).

WEID, J. M. A transição agroecológica das políticas de crédito voltadas para a agricultura familiar. Agriculturas, v. 3, n. 1, p. 18-20, 2006. 
Endereço para correspondência:

Ramonildes Alves Gomes - rnildes@hotmail.com Rua Aprígio Veloso, 882, Bairro Universitário 58.429-900 Campina Grande/PB, Brasil

ThiagoLima Matias - geouepb@yahoo.com.br Rua Baraúnas, 351, Bairro Universitário, $3^{\circ}$ andar, sala 311 58.429-500 Campina Grande/PB, Brasil

Jonatta Sousa Paulino - jonatta.15@bol.com.br Rua Aprígio Veloso, 882, Bairro Universitário 58.429-900 Campina Grande/PB, Brasil 